2020, Volume 14, International Conference Innovative Business Management \& Global Entrepreneurship (IBMAGE 2020), pages: 688-700 |

https://doi.org/10.18662/lumproc/ibmage2020/50

\section{Managing Opportunities - Achieving Smart Growth in a Digital Landscape}

\section{Denisa-Atena COSTOVICI (MEMA)', Amalia-Elena ION2}

1 Valahia University, Targoviste, Romania, denisa21co@gmail.com

${ }^{2}$ Valahia University, Targoviste, Romania, amalia.ion@live.com
Abstract: Globalization, automation, the process of reducing carbon emissions and the development of digital technology have a profound and immediate impact on the industrial sectors, jobs, profitable businesses and the way the economy and society operate and evolve. The digitization process has acquired multiple characteristics, becoming not only imperative but also universal and imminent for innovation and progress. However, Romania ranks 26th out of the $28 \mathrm{EU}$ member states in the Digital Economy and Society Index for 2020. Connectivity has improved, but the available infrastructure is still insufficient of widespread to meet the rapidly growing needs in this area. In order to improve the situation, the EU has decided to redirect the funds available to support the digitalisation of its economies and societies by setting up a new funding program, called Digital Europe, for the period 2021-2027. Therefore, in the next financial period, the Romanian state has the premises for the increasing of digitalization by accessing and using specially dedicated funds. This scientific research aims to identify areas that require technological improvements, incorporating both public institutions and private entities. Following the obtained results, untapped opportunities for digitization will be analysed and proposals will be made for the extension of the technological sphere in Romania. The main hypothesis highlights the sustainability of the economy generated by the modernization of public services and the versatility of business. The present research can provide support for reforming public services and industrial sectors and is useful in supporting the adoption of legislative measures to digitally transform a state that has the necessary know-how, qualified human resources and wide availability of high and very high speed fixed broadband networks (especially in urban areas).

Keywords: digitization; digitalization; innovation; versatility of business environment; public services; society.

How to cite: Costovici (Mema), D.-A., \& Ion, A.-E. (2020). Managing Opportunities - Achieving Smart Growth in a Digital Landscape. In M. W. Staniewski, V. Vasile, \& A. Grigorescu (vol. ed.), Lumen Proceedings: Vol. 14. International Conference Innovative Business Management \& Global Entrepreneurship (IBMAGE 2020) (pp. 688-700). Iasi, Romania: LUMEN Publishing House.

https://doi.org/10.18662/lumproc/ibmage2020/50 


\section{Introduction}

The pandemic generated by the emergence of the SARS-CoV-2 virus demonstrates the relevance of digital assets to the state economies and how networks and connectivity, data, artificial intelligence and super computers, as well as basic and advanced digital skills support economies and societies, making possible the continuation of work, tracking the spread of the virus and accelerating the search for medicines and vaccines [3]. Looking at the behaviour of the Member States as a result of the new situation, it is noted that specific measures are being introduced to mitigate the impact of the pandemic.

We consider it essential to explain the terminology digitization, digitization and digital transformation [1]. Thus, the attached table defines and outlines the main characteristics of the basic concepts that will be used in the research paper.

Table 1. The distinctions of the concepts: digitization, digitalization and digital transformation

\section{Digital Transformation}

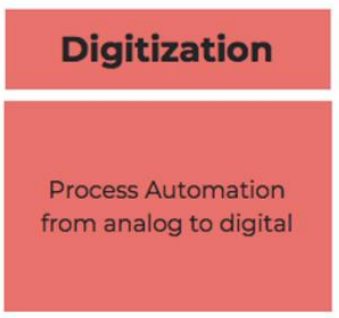

Moving from manual

input in excel to an

ERP solution
Digitalization

Use to digital

technologies to change

business models, creating

new value and revenue

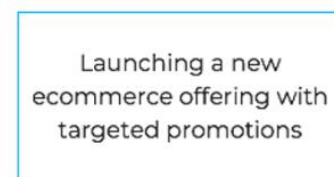

\section{Transformation}

Fundamental change in leadership, culture, and mindsets, with digital at the core enabling speed-to-value delivery of new products and services that customers love

Cross-functional teams, running concurrent customer-centric, experiments, making data-driven decisions, launching every few weeks

Source: Kasenally Alam, About Digital Transformation [10]

Digitalization has a key role in the economic prosperity, as the European Council and the European Commission have committed to structure the support for recovery, in line with the dual transition towards climate neutrality and resilient digital transformation. Within this framework, the deployment of $5 \mathrm{G}$ technology and very high capacity networks (VHCN), digital skills, business and government digitization are essential for a solid recovery. In each Member State, the progress regarding this aspect is 
monitored within the EU through the instrument [3] called the Digital Economy and Society Index (DESI).

\section{Digital Economy and Society Index for 2020}
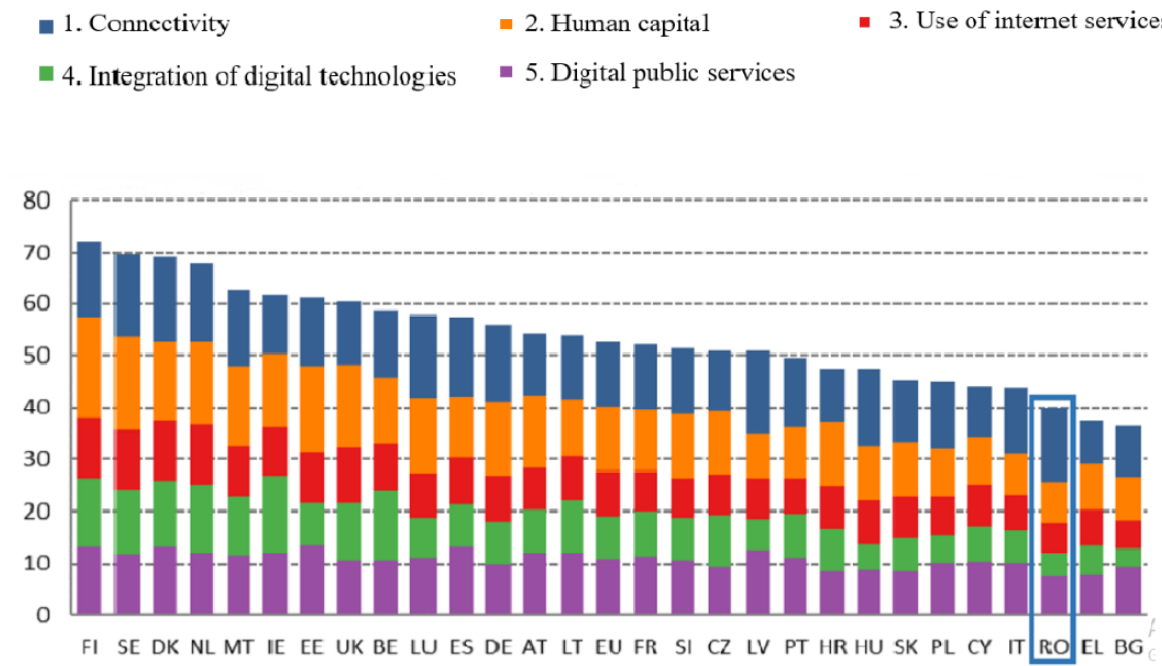

Source: European Commission, Digital Economy and Society Index for 2020 [3]

Figure 1. The latest EU Member States ranking regarding Digital Economy and Society

According to the Digital Economy and Society Index for 2020, Romania ranks 26th out of 28 EU Member States [5]. Based on data prior to the pandemic, Romania's performance was identical in four of the five DESI dimensions measured. This is due to slow progress in general, but also to political instability, as there have been four different governments in Romania in the last three years.

Romania has the best results regarding Connectivity, due to the increased use of very high-speed broadband and the wide availability of very high-capacity fixed networks, especially in urban areas. $49 \%$ of individual homes in Romania are subscribed to very high-speed broadband services (at least $100 \mathrm{Mbps}$ ), making Romania the 5th fastest in the EU. However, the digitization of the economy has lagged behind, with almost a fifth of Romanians never using the Internet and fewer than a third having only basic digital skills. 
As positive elements, Romania ranks well with Information and Communication Technology graduates, ranking fifth, with $5.6 \%$ of all graduates (EU average: 3.6\%); however, regarding the digitization of public services and the use of internet services, Romania's performance is the lowest among EU Member States. Note that the DESI 2020 index is calculated on the basis of official statistics from 2019 and does not reflect developments generated by the coronavirus pandemic.

In February 2015, Romania adopted the National Strategy on the Digital Agenda for Romania 2020, in which four areas of action were defined [12]. At present, the commitments provided in the strategy [14] and assumed by the Romanian State are unknown. The experts who prepared the DESI 2020 report state that the annotated assessments and findings must be in conjunction with the pressure on digital infrastructure and services during the pandemic and with the immediate action taken by Member States. Similarly, as Europe - with all individual Member States - gradually overcomes the pandemic, the recovery must be planned taking into account the lessons learned from this crisis situation.

It is necessary to identify and develop indicators relevant to a digital transformation and a stronger and more resilient economic recovery, namely very high capacity networks (VCNNs), 5G technology, digital skills and advanced digital technologies for businesses and public services [8]. Romania had to adapt to the new situation. Moreover, in order to cope with the crisis caused by the COVID-19 pandemic, several specific measures had been adopted, without omitting the digital domain. A software is used by the Ministry of Health to centralize medical data on the situation caused by the SARS-CoV-2 virus. A website (https://aici.gov.ro/home) has been created for companies to electronically submit the documentation necessary for the granting of technical unemployment. Another initiative (https://datafara.ro/) was created to support people who have been fired because of the COVID-19 pandemic and are actively seeking employment. Also, several websites (https://datelazi.ro/, https://cetrebuiesafac.ro/, https://fiipregatit.ro/ https://stirioficiale.ro/informatii) have been created in order to provide clear information, increase transparency, reduce panic, combat misinformation, explain risks and provide information on prevention measures [4].

A special platform (https://diasporahub.ro/) dedicated to Romanian citizens living abroad has been developed, for providing support according to their needs.

Particular emphasis has been placed on the creation of websites (https://ajutorspitale.ro/, https://rohelp.ro/ro/) to provide the necessary 
support to hospitals, as well as for the coherent and safe collection and distribution of aid [4].

According to Decision No. 370 (7th May 2020), adopted by the Romanian Government, the National Programme "Home School" was approved as well as the allocation of funds for the Ministry of Education and Research, from the Budgetary Reserve Fund available to the Government, provided for the 2020 state budget. The situation required an additional budget of 150 million RON (approximately 24 million EUR) for the Ministry of Education and Research, in order to purchase 250,000 laptops. The objective is to ensure access to distance learning activities for pupils from disadvantaged backgrounds, enrolled in pre-university education establishments.

Although these measures have been taken, the European Commission considers that government managed projects aimed at improving digital skills levels across the country are few, in relation to the need, and the results achieved to date are limited [7]. As digital infrastructure and digital skills are essential to harness the benefits of digitalization, coordinated and specific efforts are needed to improve digital skills not only in schools, but also among the workforce and the elderly.

Analysing the values presented by the DESI indicators, which are particularly relevant for the economic recovery after the crisis caused by the COVID-19 pandemic, the following were concluded, regarding the process and the perspective of digitalization:

- Romania is very advanced in terms of coverage of very high capacity networks (VHCN) and ranks 14th in the EU in terms of readiness for the use of $5 \mathrm{G}$ networks.

- On the other hand, the Romanian state lags behind in terms of indicators related to digital skills and has a poor performance in terms of digitalization of enterprises and digital public services.

- A positive aspect is the high degree of Internet connectivity. Romania ranks 11th in terms of connectivity. In 2019, Romania improved its results in terms of coverage, but stagnated in terms of utilization. Furthermore, high-speed broadband coverage has increased to $82 \%$, but is still behind most Member States (EU average is $86 \%$ ).

- Romania remains among the EU countries with the lowest performance on the integration of digital technologies in the national economy, according to the European Commission's report [3]. To blame are the slow progress in the adoption and use of online services and the political instability. Romania ranks 26th in the EU in 
digitalization, with an overall score of 40 points, slightly above the scores obtained by Greece and Bulgaria, the countries in the last two positions.

According to the Commission, the process of digitalization of the Romanian economy is largely delayed by the lack of digital skills, given the fact that almost a fifth of Romanians have never used the Internet and less than a third have only elementary level digital skills.

\section{Problem Statement}

As we pointed out above, Romania is among the last positions regarding the digital economy. As a consequence, many economic sectors are directly affected. In the following we will highlight the main dysfunctions that obscure digital development in several main areas of activity.

E-government or digital governance generically defines the use of new communication technologies and IT applications by the central and local public administration in order to streamline the activity of the administrative apparatus and increase the quality of public services [13]. Egovernment is the use, by the public sector, of information and communication technologies in order to improve the provision of information and services, encouraging citizens to participate in the decisionmaking process and to hold the government accountable in a transparent and efficient manner.

Although Romania defined in 2014 a national strategy on digitization, most of the measures taken have not been started, the rest being in an early stage of implementation.

The following are considered barriers that obstruct the implementation of digital governance in Romania [13]:

- Lack of an entity responsible with the coordination of the efforts to implement the digital strategy;

- Lack of basic digital skills to enable the use of advanced technologies by both citizens and employees of public structures;

- Migration of IT specialists;

- Lack of legislation aligned with the European framework, ensuring flexibility in the implementation of initiatives in the digital field, for example the electronic signature;

- The relatively high cost of electronic signature certificates.

Regarding the activities related to the use of e-government services, Romania registers a very low level, thus, four regions have very poor results: West and South-West Oltenia Region 9\%, North-East Region 7\% and 
Southeast Region 3\% [11]. As we pointed out above, the topic of digitizing public services in Romanian institutions is stringent.

Advantages of implementing the e-government system:

- Facilitating access to information and services provided by public administration authorities through fast and efficient service;

- Reorganization and restructuring of administrative processes, including elimination of some stages;

- Improving the exchange of information and services between central public authorities;

- Improving the quality of public services by the central public administration;

- Promoting accountability, efficiency and transparency of public services provided.

Regarding the education system, the flagged problems are:

$>$ the inadequacy and insufficiency of IT resources at central level;

$>$ the lack of significant IT resources at local level and the lack of an adequate strategy to address the problem of working tools regarding teachers, officials and students.

Existing curricula and infrastructure do not mirror the need to enhance students' digital skills. The number of very well-equipped schools from a digital point of view in Romania is significantly lower than the EU average [2]. The central systems run on an outdated infrastructure, with much lower performance than necessary, and the local systems are practically non-existent, both at the level of educational units and inspectorates. The current model of investing in education in Romania does not explicitly address inequities in education or the quality of educational infrastructure, rather amplifying socio-economic and cultural inequalities, portrayed by cleavages in the teaching and learning conditions found at county level, rural and urban communities.

After assessing the levels of digitization and deficiencies in the governmental sector, the study applies the same criteria to the private sector. Business need to adapt to the dynamics of global market and to do so certain measures need to be taken.

Business managers have responsibility for process management in their company, but frequently they assign the IT\&C department the responsibility for digitalization. The benefits of such a transition should be analyzed thoroughly by the managing structure and transmitted to the rest of employees. 
Digitalization in the business sector offers substantial opportunities to increase value but it cannot be achieved without a set of new skills [9]. The main problem is the permeability of employees to new procedures and standards that facilitate the transition. Current workers have no motivation to change their habits and show reluctance to the digitalization initiatives started by the company the work in.

In order to reach a high level of digitalization, organizations need to set clear and achievable objectives and demonstrate maturity in business process management.

\section{Aims of the research}

The purpose of the study is to identify and perform an analysis of areas that require stringent improvements in the level of digitization and digitalization. As we have already pointed out, the digital transformation in Romania has not reached the expected performances in the last decade. The research paper aims to highlight some key sectors: research and development, public services (e-government) and business environment - in which the degree of digitalization is reflected in performance and continuous development.

The article aims to be a research contribution to identify sustainable solutions to improve the digitization process, but with low costs for Romania, as most of the budget funds for 2020 had an unexpected destination - resilience to the pandemic COVID-19.

The research work can be a starting point or support in initiating legislative steps to create a legal and mandatory framework or a viable strategy for implementing digital transformation nationwide in Romania.

\section{Research Methods}

In order to fulfil the main purpose of the paper, an analysis of the documents was performed, both qualitative (official regulations, Reports and Proposals of the European Commission, Romanian Reports on the eGovernment system, National Strategy on the Digital Agenda for Romania 2020), and quantitative, processing data from other research on the Digital Economy and Society Index - country profile (European Commission).

Regarding the quantitative analysis, the digitization indicators in Romania were interpreted in relation to the data of the $28 \mathrm{EU}$ member states, aiming to establish a causal relationship between these indicators and the low level of digitization in both the public and private sectors in Romania. 
The research method used was the thematic analysis, through which the main barriers that block the digital transformation at national level were highlighted. Following the analysis, hypotheses were issued based on the stringency of the development of digital transformation in certain sectors of economic activity. This empiric research is based on directly observation of the level of digitalization from 2019-2020 period in Romania.

\section{Findings}

The process of digitalization at national level can be really expensive and in the context of budgetary distribution towards the regeneration of the economy after the effects of the COVID-19 pandemic, the Romanian state can invoke the lack of sufficient funds to this sector.

A solution for real and visible progress regarding the digital transformation of the business environment and of the public services can be considered the accessing of European funds [6]. Romania has a major opportunity for improving the level of digitization and digitalization nationwide in the next financial period.

The financial mechanism that will be available for Romania, starting from 2021 until 2027 is called SMART GROWTH, DIGITALIZATION AND FINANCIAL INSTRUMENTS OPERATIONAL PROGRAM [11].

The strategic vision of the operational program implies creating in Romania, an ecosystem that enhances the competitiveness of society in the context of technological change, starting from the development needs identified by the National Strategy and the 8 Regional Strategies for Intelligent Specialization and concentrating efforts to achieve the potential of digital technologies and creating new development opportunities for both the public system and the business environment [11].

The EU funding opportunity proposes digitization in education and culture and promotion of governance [11]. The total budget of the financial mechanism provided by the EU is 2.143 billion euros.

The general objective of the programme is to reduce disparities between Romania and other Member States, but also between regions in Romania.

The specific objectives are:

- Development of research and innovation fields;

- Endorsing of advanced technologies;

- Improving digital connectivity;

- Developing skills for smart specialisation, industrial transition and entrepreneurship [15]. 
Taking into account the wide spectrum of activities and services financed by the new operational program, it can be considered an essential support for the business environment as well. We consider that the versatility of business environment in the last decade makes the private sector more prepared for the absorption of European funds and more receptive to digital transformation than the public sector. Absorption of EU funds in order to increase business performance seems to be the optimal solution considering costs covered in overwhelming proportion of EU.

The analysis concludes as well the need to increase the capacity of Romanian research organisations in order to be able to integrate into the European Research Area. Also, another objective is to participate in European programmes, as well as transnational research. In addition to the need to find the optimal solutions for the recovery of the current situation, links should be established between emerging centres of excellence and their counterparts in other Member States. Of utmost importance is the development of mechanisms which facilitate participation in European projects and joint research programmes. The European Commission's specialists believe that market failures were mainly caused by the low level of public investment in Research and Development.

Following the data collected, we decided to identify other possible solutions to encourage digital transformation in several economic sectors.

One solution to improve the level of digitization in Romania is to stimulate the development of platforms/HUBs in key areas for Romania, which intrinsically shape the region in which they are located, having a double significance: as contributors to competitiveness, and also as catalysts for cohesion and integration. Another benefit is represented by the major impact on the qualification and education programs, increasing the competencies of the human resource, researchers and students, thus becoming tools for collaborations between different relevant actions, as well as for ensuring technology transfer.

Referring the process of digitization in education and to support egovernment, it is necessary to continue transition measures by developing IT infrastructure, corroborated with the installation of educational software (for teaching, exams). Furthermore, increased support should be granted to interventions that target digitalization and interoperability in the field of education (equipment and infrastructure, databases, software, digital platforms) for the modernization of existing digital public services.

Regarding public services (taxation, pensions, etc.), it is necessary to improve their interoperability framework, with an emphasis on cyber security and to facilitate the government's decision-making process through complex systems and solutions. 
As the funds made available to the Romanian government by the EU are non-refundable and the low percentage of digitization at national level, it is considered optimal to increase the use of these financial instruments. The results will appear on several levels:

- Reducing bureaucracy;

- Increasing transparency and efficiency through the use of modern;

- Technologies and automating administrative flows;

- Speed and efficiency in public institutions;

- Accessibility to a wider range of information;

- Better document management;

- Improving quality and reducing errors.

Analysing the good practices followed by other countries and the success of the implementation of digital initiatives, the following measures can be considered solutions in order to optimize the level of digitization, and treated as priorities:

- Designation of a government institution responsible for implementing the digital strategy;

- Amending the law on electronic signatures so that all types of signatures are recognized (electronic signature, advanced electronic signature and qualified electronic signature), thus facilitating the exchange of information and documents between citizens, business and government institutions [13];

- Implementing digital identity;

- Conventions concluded between business representatives and public institutions to optimize the flow of information (e.g. the development of a system for the electronic processing of seizures);

- E-tax: implementation of solutions for accessing, submitting and editing various forms and information related to the payment of taxes at the national level. We should mention that the more developed cities of Romania benefit from such systems; at the opposite pole being located all the other regions of the country;

- Expanding financial education initiatives in the area of digital skills;

- Extending the functionalities of the online public procurement portal so that all activities are included (bidding, deliverables, invoicing, archiving, etc.);

- Development of an online portal for registration of companies and extension of the functionalities of the Trade Register for the submission of documents in electronic format. 


\section{Conclusions}

From a dual perspective, digitization is essential for any state. On the one hand, it involves streamlining the way in which public institutions provide vital services to the population (information, services, etc.), while also being directly responsible for reducing the time required for the decision-making process. This last aspect translates into reduced costs for the state. On the other hand, digitalization favours the emergence of new businesses, and streamlines those that have been able to migrate to the virtual environment.

In the 21 st century, digitalization is a necessary condition both for profit in the case of businesses and for efficient e-government in the case of states.

Adopting the digital government model may offer solutions to acute problems both in public administration and private sector (corruption, growing global economic crisis, health care insufficiency, natural disasters).

Although Romania has had a significant economic growth in the last 20 years, it is $1.2-2.5 \%$ per year below the growth recorded by the countries in Eastern Europe that are at an advanced stage in terms of digitization of services government (e.g. Estonia, Lithuania, Latvia); Romania needs to consider maximizing digitization policies and viewing investments in the technology sector as a way to transform the economy and further drive growth.

\section{References}

[1] Chapco-Wade C. Digitization, Digitalization, and Digital Transformation: What's the Difference. Date of publication: 2018 October 21 [cited 2020 October 6]. Available from:

https://medium.com/@,colleenchapco/digitization-digitalization-and-digitaltransformation-whats-the-difference-eff1d002fbdf

[2] Dogaru GV, Costovici DA, Bitca MD. Challenges in managing the education system in 2020. International Journal of Business and Management Invention (IJBMI) [Internet]. 2020 [cited 2020 October 6]; pp: 51-57. Available from: https://doi.org/10.35629/8028

[3] European Commission. Digital Economy and Society Index for 2020. Date of publication: 2019 June 19 [cited 2020 October 2], pp. 1-8. Available from: https://ec.europa.eu/digital-single-market/en/desi

[4] European Commission. Digital Economy and Society Index for Romania 2020. Date of publication: 2020 June 11 [cited 2020 October 2], pp. 1-15. 
Available from:

https://ec.europa.eu/romania/news/20200611 raport rezilienta digitala ro

[5] European Commission. Digital scoreboard. Date of publication: 2018

September [cited 2020 October 6]. Available

from: http://ec.europa.eu/digital-agenda/en/scoreboard

[6] European Commission. EU budget for the future. Date of publication: 2020

July 21. [cited 2020 October 6]. Available from:

https://ec.europa.eu/commission/future-europe/eu-budget-future en

[7] European Commission. Regional development and cohesion 2020: the new framework at a glance. Date of publication: 2018 May 29 [cited 2020 October 1]. Available from: https://ec.europa.eu/commission/publications/regionaldevelopment-and-cohesion en beyond

[8] European Parliament. Digital Agenda for Europe. Date of publication: 2019 May 8 [cited 2020 September 16]._Available from https://ec.europa.eu/digitalsingle-market/en/europe-2020-strategy

[9] Fitzgerald M, Kruschwitz N, Bonnet D. Embracing Digital Technology. A New Strategic Imperative. MITSloan Management Review [Internet]. Date of publication: 7 October 2013 [cited 2020 September 22]. pp. 6-11. Available from: https://sloanreview.mit.edu/projects/embracing-digital-technology/

[10] Kasenally A. About Digital Transformation. Date of publication: 2018 October 8 [cited 2020 September 21]. Available from: http://blog.reddot.mu/author/ak/

[11] Ministry of European Funds. Smart growth, digitalization and financial instruments operational program. Date of publication: 2020 June [cited 2020 September 21]. Available from: http://mfe.gov.ro/minister/perioade-deprogramare/perioada-2021-2027/

[12] Ministry of Communications and Information Society. Digital agenda for Romania: 2020. Date of publication: 2015 April 7 [cited 2020 September 28]. Available from: https://www.comunicatii.gov.ro/agenda-digitala-pentruromania-2020/

[13] PricewaterhouseCoopers Corporate. Research on implementation Digital Governance in Romania. Date of publication: 2018 September [cited 2020 September 25]. Available from: https://www.arb.ro/wpcontent/uploads/Studiu-e-Guvernare.pdf

[14] The Government of Romania. National Strategy on the Digital Agenda for Romania. Date of publication: 2015 August 19 [cited 2020 September 23]. Available from: https://epale.ec.europa.eu/sites/default/files/strategianationala-agenda-digitala-pentru-romania-20202c-20-feb.2015.pdf

[15] Viola R. European Dimension of the Digital Economy. Date of publication: 2018 September 28. [cited 2020 September 23]. Available from: https://ec.europa.eu/digital-single-market/en/blogposts/europeandimension-digital-economy 